\title{
Editorial: Metabolic Changes After Kidney Transplantation
}

\author{
Ekamol Tantisattamo ${ }^{1,2,3}$, Bing T. Ho ${ }^{4}$ and Biruh T. Workeneh ${ }^{5 *}$ \\ ${ }^{1}$ Harold Simmons Center for Kidney Disease Research and Epidemiology, Division of Nephrology, Hypertension and Kidney \\ Transplantation, Department of Medicine, University of California, Irvine School of Medicine, Orange, CA, United States, \\ ${ }^{2}$ Nephrology Section, Department of Medicine, Tibor Rubin Veterans Affairs Medical Center, Veterans Affairs Long Beach \\ Healthcare System, Long Beach, CA, United States, ${ }^{3}$ Multi-Organ Transplant Center, Section of Nephrology, Department of \\ Internal Medicine, William Beaumont Hospital, Oakland University William Beaumont School of Medicine, Royal Oak, MI, \\ United States, ${ }^{4}$ Comprehensive Transplant Center, Division of Nephrology and Hypertension, Department of Medicine, \\ Northwestern University Feinberg School of Medicine, Chicago, IL, United States, ${ }^{5}$ Section of Nephrology, University of \\ Texas MD Anderson Cancer Center, Houston, TX, United States
}

Keywords: chronic kidney disease-mineral bone disorders, electrolyte disturbances, hypertension, living donor, metabolic changes, metabolic syndrome, kidney transplantation, nutrition

\section{Editorial on the Research Topic}

\section{OPEN ACCESS}

Edited by:

Xu-jie Zhou,

Peking University First Hospital, China

Reviewed by:

Antoine Thierry

Centre Hospitalier Universitaire (CHU)

de Poitiers, France

Gaurav Gupta,

Virginia Commonwealth University,

United States

*Correspondence:

Biruh T. Workeneh

btworkeneh@mdanderson.org

Specialty section:

This article was submitted to Nephrology,

a section of the journa

Frontiers in Medicine

Received: 14 May 2021 Accepted: 31 May 2021 Published: 08 July 2021

Citation:

Tantisattamo E, Ho BT and Workeneh BT (2021) Editorial: Metabolic Changes After Kidney

Transplantation

Front. Med. 8:709644.

doi: 10.3389/fmed.2021.709644

\section{Metabolic Changes After Kidney Transplantation}

Kidney transplantation is the treatment of choice for those nearing or suffering from end-stage kidney disease (ESKD) (1). Transplantation provides a significant survival benefit, restoring kidney glomerular filtration and homeostatic functions, including fluid and electrolyte balance. Furthermore, it improves the quality of life, freeing patients from the obligation to have regular dialysis. Despite all the articulated benefits of kidney transplant recipients, the cardiovascular and overall mortality risk remains high compared to the general population (2). Indeed cardiovascular diseases (CVD) occur at high rates and are the most common cause of mortality in kidney transplant recipients (3). Both traditional and non-traditional risk factors of CVD in kidney transplant recipients contribute to morbidity and mortality. Some risk factors are modifiable, such as diet or behavioral, but other determinants are difficult or impossible to modify. In addition to describing various metabolic challenges associated with kidney transplantation, the article series explores the opportunity to intervene and improve kidney allograft and patient outcomes.

Metabolic alteration and chronic inflammation appear early in chronic kidney disease (CKD) stages and progress through ESKD, making CKD one of the most important cardiovascular risk factors. After successful kidney transplantation, these changes may become normalized or be persist. In this timely topic of metabolic changes after kidney transplantation, five articles address various topics related to common metabolic changes post-kidney transplantation, including nutrition for kidney transplant recipients, electrolytes and acid-base disturbances, chronic kidney disease-mineral bone disorders (CKD-MBD), and post-transplant hypertension. Since successful kidney transplantation also depends on kidney donor factors, an article related to inflammatory change and biomarkers in living kidney donors was highlighted.

Diet and nutrition play an essential role in the slow progression of CKD (4). Likewise, nutrition in kidney transplantation is one of the critical components in caring for kidney transplant recipients to slow the progression of kidney allograft function and mitigate poor transplant outcomes. Despite evidence that has shown the benefit of dietary intervention on kidney health, particularly dietary protein intake in the CKD population (4-6), there is a lack 
of studies regarding dietary interventions to slow the progression of kidney allograft function (7-12). In addition, since kidney transplantation involves the dynamic process from pre-, peri-, and post-transplant periods when physical stress and intensity of immunosuppressive medications have been changed, extrapolating data or clinical practice guidelines from general, CKD, or ESKD populations may not be ideal. Nolte Fong and Moore reviewed evidence related to nutritional complications after kidney transplantation, both macronutrients including fat, protein, carbohydrate, and micronutrients, including phosphorus, magnesium, vitamin D. Nutrition trends, dietary intervention, and recommended diet intervention in kidney transplantation were discussed.

Electrolyte and acid-base disturbances are prevalent in kidney transplant recipients, and the pathogenesis of some of these are different from those in CKD. Although regaining kidney function but possibly at the suboptimal level in immunosuppressive milieu, some electrolyte disturbances are almost universal. Pathogenesis of post-transplant electrolyte and acid-base imbalances involve the interplay between non-immunologic and immunologic factors. The non-immunological factors can be persistent from pre- through post-transplant periods, whereas immunological factors occurring post-transplant result primarily from immunosuppressive medications. Pochineni and Rondon-Berrios presented an excellent review of electrolyte and acid-base disorders commonly seen in kidney transplant recipients, including hyperkalemia, metabolic acidosis, hypercalcemia, hypomagnesemia, and hypophosphatemia. The epidemiology, pathogenesis, and clinical manifestations were reviewed, and recommendations for management were summarized.

CKD-MBD is one of the fascinating metabolic changes after successful kidney transplantation, and there has been a rapid growth of evidence in kidney transplantation. Laboratory components, bone disorders, and tissue calcification may not be reversible after kidney transplantation. Even if they are reversed toward normalized values or status during non$\mathrm{CKD}$, the pattern can vary widely. Vangala et al. provided a comprehensive review in all clinically relevant aspects of CKD-MBD after kidney transplantation, including the pathophysiology of CKD-MBD from pre- through posttransplantation, clinical presentations, detailed and separated disorders of bone and mineral metabolism related to CKDMBD including calcium, phosphorus, parathyroid hormone, and vitamin $\mathrm{D}$, common bone diseases in $\mathrm{CKD}-\mathrm{MBD}$ including renal osteodystrophy, osteopenia, osteoporosis, and osteomalacia. Investigations for biochemical markers of CKD-MBD and bone

\footnotetext{
Abbreviations: CMV, cytomegalovirus; CKD, chronic kidney disease; CKD-MBD, chronic kidney disease-mineral bone disorders; $\mathrm{CO}_{2}$, total carbon dioxide; CPAP, continuous positive airway pressure; CsA, cyclosporine; $\mathrm{CNI}$, calcineurin inhibitors; CVD, cardiovascular disease; DCC, distal convoluted tubule; ENaC, epithelial sodium channel; ESKD, end-stage kidney disease; FGF23, fibroblast growth factor 23; HTN, hypertension; IV, intravenous; $\mathrm{K}$, potassium; MBD, mineral bone disorder; Mg, magnesium; NCC, thiazide-sensitive sodium-chloride cotransporter; PTH, parathyroid hormone; RAAS, renin-angiotensin aldosterone; RTA, renal tubular acidosis; TMP/SMX, trimethoprim/sulfamethoxazole; 25(OH)D, total 25-hydroxy vitamin D.
}

health assessment, as well as pharmacological and surgical management for CKD-MBD, were discussed.

Hypertension is one of the clusters of metabolic disorders in metabolic syndrome (13) and one of the most common but modifiable risk factors for CVD (14). From the advanced stage of CKD to post-transplant periods, hypertension is almost universal. Contributing factors of post-transplant hypertension involve both factors resulted from complications of ESKD and transplant-related factors. The ESKD-related factors include volume overload, stimulated renin-angiotensin-aldosterone system, sympathetic nervous system activation, arterial stiffness, vascular endothelial dysfunction, sleep apnea, erythropoiesisstimulating agents (15). After successful kidney transplantation, both non-immunological factors, which endure from the ESKD period, and immunological factors, particularly associated with immunosuppressive medications, contribute to post-transplant hypertension. Tantisattamo et al. reviewed several aspects of post-transplant hypertension, including epidemiology, pathogenesis primarily related to immunosuppression. Obtaining an accurate blood pressure measurement and reading was emphasized by using 24-h ambulatory blood pressure monitoring. The advantages and disadvantages of different types of commonly used antihypertensive medications in the setting of immunosuppression and potential electrolyte and acid-base disturbances were compared and contrasted. Well-recognized but under-diagnosed causes of post-transplant hypertension, including transplant renal artery stenosis and obstructive sleep apnea, were reviewed. Non-pharmacological management for uncontrolled post-transplant hypertension, including renal nerve denervation and native nephrectomy, were discussed.

Although the metabolic changes in kidney transplant recipients, including nutrition-related changes, acid-base disturbances, CKD-MBD, and hypertension, as nonimmunological factors, contribute to poor transplant outcomes both kidney allograft and patient survivals, these factors interconnect with immunological factors (Table $\mathbf{1}$ and Figure 1). Therapy of modifying immunosuppressive medications can be limited from potentially adverse kidney allograft outcomes; several interventions for non-immunological factors are available with varied effectiveness. While medical therapies are the most frequently utilized option and improve or normalize acid-base, electrolytes, MBP markers, long-term transplant outcomes may not be different from non-medical therapies, but potential medication side effects may occur. Dietary modification is beneficial and supplementary for the medical therapies for all post-transplant electrolyte and acid-base disturbances and hypertension. Furthermore, surgical and procedural interventions for post-transplant CKD-MBD and hypertension are options if medical or dietary interventions are ineffective, although data regarding long-term transplant outcomes are required (Figure 1).

Finally, a provocative prospective cohort study by Díaz-de la Cruz et al. investigated the inflammatory state in living kidney donors. Several long-term studies have demonstrated kidney donation safety in carefully selected donors $(58,59)$. However, there is a small fraction that develops CKD, and it is 
TABLE 1 | Prevalence and pathogenesis of metabolic changes after kidney transplantation.

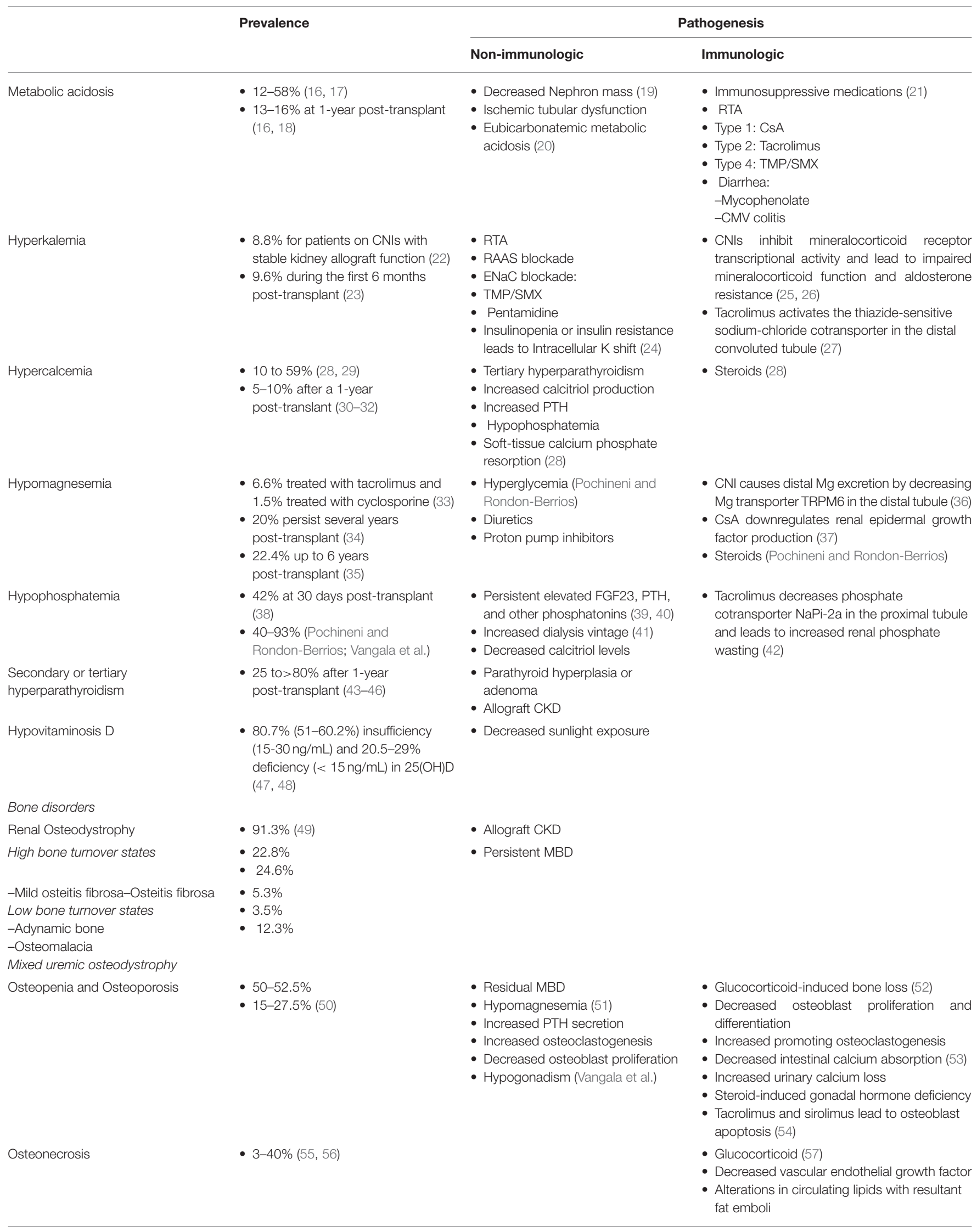


TABLE 1 | Continued

Prevalence

Hypertension

\section{- 24-90\% (Tantisattamo et al.)}

- Volume overload

- Pain

- Rebound hypertension

- Obesity

- FGF23

- Transplant renal artery stenosis

- Obstructive sleep apnea

- Sympathetic over activity

\section{Pathogenesis}

Immunologic

- Increased apoptosis of osteoblasts, osteocytes and endothelial cells

- Adipogenesis, procoagulant state

- Modulation of vasoactive mediators

- Increased intraosseous pressure leads to ischemia and necrosis

- Immunosuppressive medications

- $\mathrm{CNls}$

- Steroids

- Hypertensive donor kidneys

- Chronic renal allograft dysfunction

CMV, cytomegalovirus; CSA, cyclosporine; CNI, calcineurin inhibitors; ENaC, epithelial sodium channel; FGF23, fibroblast growth factor 23; K, potassium; PTH, parathyroid hormone; RAAS, renin-angiotensin aldosterone; RTA, renal tubular acidosis; TMP/SMX, trimethoprim/sulfamethoxazole; 25(OH)D, total 25-hydroxy vitamin D.

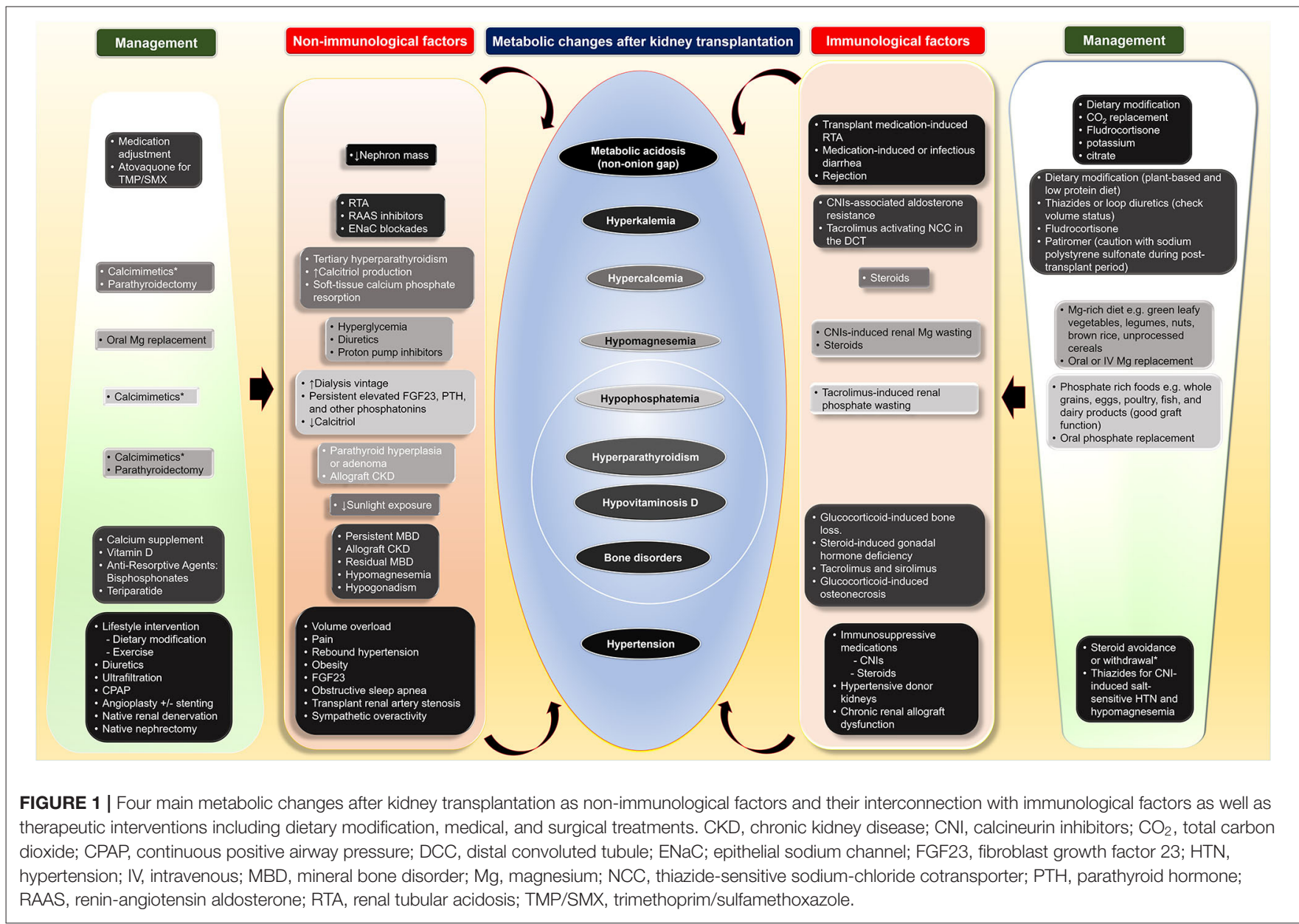

important to investigate why this happens to increase the safety of donation. The authors examined patterns of pro-inflammatory cytokines and markers of oxidative stress and found significant changes in the oxidative state markers after 6-months postdonation. The study's findings add to what is known about metabolic changes after kidney donation, and additional study 
is required to characterize alterations further and correlate them with clinical importance.

While improved kidney function after successful kidney transplantation significantly lowers kidney transplant recipients' mortality, profound metabolic alterations affect nutrition, electrolyte, acid-base balance, mineral bone metabolism, and insulin resistance. Metabolic syndrome and post-transplant diabetes are common, and cardiovascular damage resulting from the alterations in metabolism is accelerated, leading to excess mortality compared to the general non-CKD population, which still exist or are partially improved. Uncorrected, these metabolic changes can adversely affect post-transplant kidney allograft and patient outcomes, particularly morbidity and mortality from CVD. Living kidney donation is also the main component of successful kidney transplantation, and further investigation in the file of metabolic and inflammation should be another novel area of research.

\section{REFERENCES}

1. Suthanthiran M, Strom TB. Renal transplantation. N Engl J Med. (1994) 331:365-76. doi: 10.1056/NEJM199408113310606

2. Arend SM, Mallat MJ, Westendorp RJ, et al. Patient survival after renal transplantation; more than 25 years follow-up. Nephrol Dial Transplant. (1997) 12:1672-9. doi: 10.1093/ndt/12.8.1672

3. Rangaswami J, Mathew RO, Parasuraman R, et al. Cardiovascular disease in the kidney transplant recipient: epidemiology, diagnosis and management strategies. Nephrol Dial Transplant. (2019) 34:760-73. doi: 10.1093/ndt/ gfz053

4. Ko GJ, Obi Y, Tortorici AR, et al. Dietary protein intake and chronic kidney disease. Curr Opin Clin Nutr Metab Care. (2017) 20:77-85. doi: 10.1097/MCO.0000000000000342

5. Kalantar-Zadeh K, Kramer HM, Fouque D. High-protein diet is bad for kidney health: unleashing the taboo. Nephrol Dial Transplant. (2020) 35:14. doi: $10.1093 / \mathrm{ndt} / \mathrm{gfz} 216$

6. Ko GJ, Rhee CM, Kalantar-Zadeh K, et al. The Effects of High-Protein Diets on Kidney Health and Longevity. J Am Soc Nephrol. (2020) 31:166779. doi: 10.1681/ASN.2020010028

7. Cogan MG, Sargent JA, Yarbrough SG, et al. Prevention of prednisone-induced negative nitrogen balance. Effect of dietary modification on urea generation rate in patients on hemodialysis receiving high-dose glucocorticoids. Ann Intern Med. (1981) 95:158-61. doi: 10.7326/0003-4819-95-2-158

8. Whittier FC, Evans DH, Dutton S, et al. Nutrition in renal transplantation. Am J Kidney Dis. (1985) 6:405-11. doi: 10.1016/S0272-6386(85)80103-7

9. Rosenberg ME, Salahudeen AK, Hostetter TH. Dietary protein and the reninangiotensin system in chronic renal allograft rejection. Kidney Int Suppl. (1995) 52:S102-6.

10. Bernardi A, Biasia F, Piva M, et al. Dietary protein intake and nutritional status in patients with renal transplant. Clin Nephrol. (2000) 53 (Suppl 3-5).

11. Bernardi A, Biasia F, Pati T, et al. Long-term protein intake control in kidney transplant recipients: effect in kidney graft function and in nutritional status. Am J Kidney Dis. (2003) 41(3 Suppl 1):S146-52. doi: 10.1053/ajkd.2003.50105

12. Chadban S, Chan M, Fry K, et al. The CARI guidelines. Protein requirement in adult kidney transplant recipients. Nephrology (Carlton). (2010) 15 (Suppl. 1):S68-71. doi: 10.1111/j.1440-1797.2010.01238.x

13. Cornier MA, Dabelea D, Hernandez TL, et al. The metabolic syndrome. Endocr Rev. (2008) 29:777-822. doi: 10.1210/er.2008-0024

14. Collaborators GBDRF. Global, regional, and national comparative risk assessment of 84 behavioural, environmental and occupational, and metabolic risks or clusters of risks for 195 countries and territories, 1990-2017: a

\section{AUTHOR CONTRIBUTIONS}

$\mathrm{ET}, \mathrm{BH}$, and $\mathrm{BW}$ participated in designing the manuscript's topics and detail, writing the manuscript, and approved the manuscript's submitted version. All authors contributed to the article and approved the submitted version.

\section{FUNDING}

This work was supported by a research grant from the Division of Nephrology, Hypertension and Kidney Transplantation, Department of Medicine, University of California Irvine School of Medicine.

\section{ACKNOWLEDGMENTS}

We appreciate our patients for the knowledge and experience we gain from clinical care and research.

systematic analysis for the Global Burden of Disease Study (2017). Lancet. (2018) 392:1923-94. doi: 10.1016/S0140-6736(18)32225-6

15. Sarafidis PA, Persu A, Agarwal R, et al. Hypertension in dialysis patients: a consensus document by the European Renal and Cardiovascular Medicine (EURECA-m) working group of the European Renal Association-European Dialysis and Transplant Association (ERA-EDTA) and the Hypertension and the Kidney working group of the European Society of Hypertension (ESH). J Hypertens. (2017) 35:657-76. doi: 10.1093/ndt/gfw433

16. Messa PG, Alfieri C, Vettoretti S. Metabolic acidosis in renal transplantation: neglected but of potential clinical relevance. Nephrol Dial Transplant. (2016) 31:730-6. doi: 10.1093/ndt/gfv098

17. Ritter A, Mohebbi N. Causes and consequences of metabolic acidosis in patients after kidney transplantation. Kidney Blood Press Res. (2020) 45:792801. doi: 10.1159/000510158

18. Schwarz C, Benesch T, Kodras $\mathrm{K}$, et al. Complete renal tubular acidosis late after kidney transplantation. Nephrol Dial Transplant. (2006) 21:261520. doi: 10.1093/ndt/gfl211

19. Park S, Kang E, Park S, et al. Metabolic Acidosis and Long-Term Clinical Outcomes in Kidney Transplant Recipients. J Am Soc Nephrol. (2017) 28:1886-97. doi: 10.1681/ASN.2016070793

20. Raphael KL, Kraut JA. Assessing acid-base status in patients with CKD: does measurement of blood pH matter? Am J Kidney Dis. (2021) 77:911. doi: $10.1053 /$ j.ajkd.2020.08.005

21. Rodriguez Soriano J. Renal tubular acidosis: the clinical entity. J Am Soc Nephrol. (2002) 13:2160-70. doi: 10.1097/01.ASN.0000023430.92674.E5

22. Bussalino E, Panaro L, Marsano L, et al. Prevalence and clinical correlates of hyperkalemia in stable kidney transplant recipients. Intern Emerg Med. (2021) doi: 10.1007/s11739-021-02649-4

23. Christie E, Okel J, Gowrishankar M. Hyperkalemia in the early post renal transplant period. (2018) 102:S597. doi: 10.1097/01.tp.0000543485.27 703.d0

24. Rosenbaum R, Hoffsten PE, Cryer P, et al. Hyperkalemia after renal transplantation. Occurrence in a patient with insulin-dependent diabetes. Arch Intern Med. (1978) 138:1270-2. doi: 10.1001/archinte.138.8.1270

25. Deppe CE, Heering PJ, Viengchareun S, et al. Cyclosporine a and FK506 inhibit transcriptional activity of the human mineralocorticoid receptor: a cell-based model to investigate partial aldosterone resistance in kidney transplantation. Endocrinology. (2002) 143:1932-41. doi: 10.1210/endo.143.5.8821

26. Heering PJ, Kurschat C, Vo DT, et al. Aldosterone resistance in kidney transplantation is in part induced by a down-regulation of mineralocorticoid receptor expression. Clin Transplant. (2004) 18:18692. doi: 10.1046/j.1399-0012.2003.00154.x 
27. Hoorn EJ, Walsh SB, McCormick JA, et al. The calcineurin inhibitor tacrolimus activates the renal sodium chloride cotransporter to cause hypertension. Nat Med. (2011) 17:1304-9. doi: 10.1038/nm.2497

28. Messa P, Cafforio C, Alfieri C. Clinical impact of hypercalcemia in kidney transplant. Int J Nephrol. (2011) 2011:906832. doi: 10.4061/2011/906832

29. Amin T, Coates PT, Barbara J, et al. Prevalence of hypercalcaemia in a renal transplant population: a single centre study. Int J Nephrol. (2016) 2016:7126290. doi: 10.1155/2016/7126290

30. Massari PU. Disorders of bone and mineral metabolism after renal transplantation. Kidney Int. (1997) 52:1412-21. doi: 10.1038/ki.1997.469

31. Reinhardt W, Bartelworth H, Jockenhovel F, et al. Sequential changes of biochemical bone parameters after kidney transplantation. Nephrol Dial Transplant. (1998) 13:436-42. doi: 10.1093/ndt/13.2.434

32. Evenepoel P, Van Den Bergh B, Naesens M, et al. Calcium metabolism in the early posttransplantation period. Clin J Am Soc Nephrol. (2009) 4:66572. doi: 10.2215/CJN.03920808

33. Margreiter R, European Tacrolimus vs Ciclosporin Microemulsion Renal Transplantation Study G. Efficacy and safety of tacrolimus compared with ciclosporin microemulsion in renal transplantation: a randomised multicentre study. Lancet. (2002) 359:741-6. doi: 10.1016/S0140-6736(02)07875-3

34. Van Laecke S, Van Biesen W. Hypomagnesaemia in kidney transplantation. Transplant Rev (Orlando). (2015) 29:154-60. doi: 10.1016/j.trre.2015.05.002

35. Van de Cauter J, Sennesael J, Haentjens P. Long-term evolution of the mineral metabolism after renal transplantation: a prospective, single-center cohort study. Transplant Proc. (2011) 43:34705. doi: 10.1016/j.transproceed.2011.09.030

36. Nijenhuis T, Hoenderop JG, Bindels RJ. Downregulation of $\mathrm{Ca}(2+)$ and $\mathrm{Mg}(2+)$ transport proteins in the kidney explains tacrolimus (FK506)induced hypercalciuria and hypomagnesemia. J Am Soc Nephrol. (2004) 15:549-57. doi: 10.1097/01.ASN.0000113318.56023.B6

37. Ledeganck KJ, De Winter BY, Van den Driessche A, et al. Magnesium loss in cyclosporine-treated patients is related to renal epidermal growth factor downregulation. Nephrol Dial Transplant. (2014) 29:1097-102. doi: 10.1093/ndt/gft498

38. Ghorbani M, Ossareh S. Early postkidney transplantation hypophosphatemia. J Res Med Sci. (2020) 25:36. doi: 10.4103/jrms.JRMS_452_19

39. Evenepoel P, Naesens M, Claes K, et al. Tertiary 'hyperphosphatoninism' accentuates hypophosphatemia and suppresses calcitriol levels in renal transplant recipients. Am J Transplant. (2007) 7:1193200. doi: 10.1111/j.1600-6143.2007.01753.x

40. Han SY, Hwang EA, Park SB, et al. Elevated fibroblast growth factor 23 levels as a cause of early post-renal transplantation hypophosphatemia. Transplant Proc. (2012) 44:657-60. doi: 10.1016/j.transproceed.2011.11.046

41. Tomida K, Hamano T, Ichimaru N, et al. Dialysis vintage and parathyroid hormone level, not fibroblast growth factor-23, determines chronicphase phosphate wasting after renal transplantation. Bone. (2012) 51:72936. doi: 10.1016/j.bone.2012.06.027

42. Sakhaee K. Post-renal transplantation hypophosphatemia. Pediatr Nephrol. (2010) 25:213-20. doi: 10.1007/s00467-009-1252-4

43. Egbuna OI, Taylor JG, Bushinsky DA, et al. Elevated calcium phosphate product after renal transplantation is a risk factor for graft failure. Clin Transplant. (2007) 21:558-66. doi: 10.1111/j.1399-0012.2007.00690.x

44. Yakupoglu HY, Corsenca A, Wahl P, et al. Posttransplant acidosis and associated disorders of mineral metabolism in patients with a renal graft. Transplantation. (2007) 84:1151-7. doi: 10.1097/01.tp.0000287430.19960.0e

45. Wolf M, Weir MR, Kopyt N, et al. A prospective cohort study of mineral metabolism after kidney transplantation. Transplantation. (2016) 100:18493. doi: 10.1097/TP.0000000000000823
46. Al-Moasseb Z, Aitken E. Natural history of serum calcium and parathyroid hormone following renal transplantation. Transplant Proc. (2016) 48:328591. doi: 10.1016/j.transproceed.2016.09.050

47. Ewers B, Gasbjerg A, Moelgaard C, et al. Vitamin D status in kidney transplant patients: need for intensified routine supplementation. Am J Clin Nutr. (2008) 87:431-7. doi: 10.1093/ajcn/87.2.431

48. Poli de Figueiredo SM, Magalhaes AO, Malafronte P, et al. Prevalence of hypovitaminosis $\mathrm{D}$ and the different-dose cholecalciferol supplementation effects on renal transplant recipients. Saudi J Kidney Dis Transpl. (2016) 27:929-35. doi: 10.4103/1319-2442.190839

49. Lehmann G, Ott U, Stein G, et al. Renal osteodystrophy after successful renal transplantation: a histomorphometric analysis in 57 patients. Transplant Proc. (2007) 39:3153-8. doi: 10.1016/j.transproceed.2007. 10.001

50. Marcen R, Caballero C, Uriol O, et al. Prevalence of osteoporosis, osteopenia, and vertebral fractures in long-term renal transplant recipients. Transplant Proc. (2007) 39:2256-8. doi: 10.1016/j.transproceed.2007. 07.073

51. Sakaguchi Y, Hamano T, Wada A, et al. Magnesium and risk of hip fracture among patients undergoing hemodialysis. J Am Soc Nephrol. (2018) 29:9919. doi: 10.1681/ASN.2017080849

52. O'Brien CA, Jia D, Plotkin LI, et al. Glucocorticoids act directly on osteoblasts and osteocytes to induce their apoptosis and reduce bone formation and strength. Endocrinology. (2004) 145:1835-41. doi: 10.1210/en.2003-0990

53. Canalis E, Mazziotti G, Giustina A, et al. Glucocorticoid-induced osteoporosis: pathophysiology and therapy. Osteoporos Int. (2007) 18:1319-28. doi: 10.1007/s00198-007-0394-0

54. Martin-Fernandez M, Rubert M, Montero M, et al. Effects of Cyclosporine, Tacrolimus, and Rapamycin on Osteoblasts. Transplant Proc. (2017) 49:221924. doi: 10.1016/j.transproceed.2017.07.005

55. Parfrey PS, Farge D, Parfrey NA, et al. The decreased incidence of aseptic necrosis in renal transplant recipients-a case control study. Transplantation. (1986) 41:182-7. doi: 10.1097/00007890-198602000-00010

56. Nayagam LS, Rajan SG, Khandelwal $\mathrm{N}$, et al. Bilateral femoral capital avascular necrosis in a renal transplant recipient on tacrolimus-based immunosuppression. Nephrol Dial Transplant. (2005) 20:2262-4. doi: 10.1093/ndt/gfh982

57. Kerachian MA, Seguin C, Harvey EJ. Glucocorticoids in osteonecrosis of the femoral head: a new understanding of the mechanisms of action. J Steroid Biochem Mol Biol. (2009) 114:121-8. doi: 10.1016/j.jsbmb.2009. 02.007

58. Ibrahim HN, Foley R, Tan L, et al. Long-term consequences of kidney donation. N Engl J Med. (2009) 360:459-69. doi: 10.1056/NEJMoa0804883

59. Fournier C, Pallet N, Cherqaoui $Z$, et al. Very long-term follow-up of living kidney donors. Transpl Int. (2012) 25:38590. doi: 10.1111/j.1432-2277.2012.01439.x

Conflict of Interest: The authors declare that the research was conducted in the absence of any commercial or financial relationships that could be construed as a potential conflict of interest.

Copyright (C) 2021 Tantisattamo, Ho and Workeneh. This is an open-access article distributed under the terms of the Creative Commons Attribution License (CC BY). The use, distribution or reproduction in other forums is permitted, provided the original author(s) and the copyright owner(s) are credited and that the original publication in this journal is cited, in accordance with accepted academic practice. No use, distribution or reproduction is permitted which does not comply with these terms. 